\title{
Prevalence and Seasonal Variation of Different Respiratory Pathogens in Post-Weaned Pigs with Signs of Clinical Respiratory Disease Using a Tracheobronchial Swab Sampling Technique: An Update from Belgium and the Netherlands
}

\begin{abstract}
Vangroenweghe FACJ ${ }^{1,2 *}$
${ }^{1}$ BU Swine \& Ruminants, Elanco Animal Health, Plantijn en Moretuslei 1A, Antwerpen 2018, Belgium

${ }^{2}$ Unit of Porcine Health Management, Faculty of Veterinary Medicine, Ghent University, Salisburylaan 133, Merelbeke 9820, Belgium

*Corresponding author: Vangroenweghe FACJ , BU Swine \& Ruminants, Elanco Animal Health, Plantijn en Moretuslei 1A, Antwerpen 2018, Belgium
\end{abstract}

Received: December 02, 2021; Accepted: J anuary 03, 2022; Published: J anuary 10, 2022

\begin{abstract}
Besides Mycoplasma hyopneumoniae ( $M$. hyopneumoniae), many other viruses and bacteria can concurrently be present in pigs. These pathogens can provoke clinical signs, known as porcine respiratory disease complex (PRDC). A sampling technique on live animals, namely tracheobronchial swab (TBS) sampling, was applied to detect the major PRDC pathogens in pigs using PCR. The objective was to determine prevalence of different PRDC pathogens and their seasonal variations in Belgium and the Netherlands. A total of 600 pig farms and 9,000 post-weaned piglets were sampled using TBS over a 4-year period. TBS samples were analyzed using MPCR and results were categorized and analyzed according to the season of sampling. In Belgium, 53.8\% of the sampled farms were PRRSV-positive, followed by M. hyopneumoniae (48.8\%) and IAV-S (40.3\%), whereas only $20.6 \%$ of the farms were detected PCV-2positive. In the Netherlands, a similar percentage of farms were detected positive for PRRSV (51.4\%) and IAV-S (49.1\%), whereas a lower percentage of farms was M. hyopneumoniae-positive (32.4\%) and only $8.0 \%$ was detected PCV-2-positive. Combined infections consisted of $M$. hyopneumoniae - PRRSV, PRRSV - IAV-S, and M. hyopneumoniae - PRRSV - IAV-S in both countries. In Belgium, the combination of $M$. hyopneumoniae - PRRSV - PCV-2 also had a relevant prevalence. For all analyzed PRDC pathogens, clear variations among different seasons could be detected. In conclusion, the present study showed that many respiratory pathogens are present during the post-weaning period, which may complicate the clinical picture of respiratory diseases, and their prevalence may vary among seasons.
\end{abstract}

Keywords: PRDC; Tracheobronchial swabs; Prevalence; Swine

\section{Introduction}

Porcine respiratory disease complex (PRDC) is a multifactorial disease in post-weaned and growing pigs [1], provoked by a combination of several infectious viral and bacterial pathogens, environmental stressors, differences in production systems, and management practices [2-4]. The disease, characterized by pneumonia and reduced growth performance, is an economically significant respiratory disorder of post-weaned and finishing pigs, and remains a challenge to the swine industry worldwide. Multiple agents were reported to be associated with PRDC, including the major pathogens porcine reproductive and respiratory syndrome virus (PRRSV), Mycoplasma hyopneumoniae (M. hyopneumoniae), influenza A virus in swine (IAV-S), and porcine circovirus type 2 (PCV-2) $[5,6]$. Infection with each single pathogen does not necessarily result in appearance of symptoms, but complex infections with a variety of pathogens can develop severe conditions. Mycoplasma hyopneumoniae, the etiological agent of enzootic pneumonia [7,8], may act as a facilitator to other primary pathogens such as PRRSV
[9,10], IAV-S [2,11,12], and PCV-2 [13,14]. Mycoplasma infections provoke a chronic respiratory disease characterized by a chronic, non-productive cough, resulting in economic losses due to reduced growth rate, poorer feed conversion, increased medication use and a higher susceptibility to secondary pathogens, such as $P$. multocida and A. pleuropneumoniae [7]. Porcine reproductive and respiratory syndrome virus has different clinical signs, of which the respiratory form primarily affects growing and finishing pigs leading to interstitial pneumonia, which induces respiratory signs [15]. Due to its immunodepressive effects, PRRSV increases the susceptibility of pigs to secondary bacterial and viral infection [16-21]. Concurrent infections with PRRSV, PCV-2, and M. hyopneumoniae have been associated with more severe disease and higher mortality [16,22-24]. Swine influenza is mainly caused by influenza type A viruses, of which several subtypes of IAV-S have become enzootic in the pig population. Currently, three IAV-S subtypes, namely H1N1, H2N1, and H3N2, are circulating among pigs worldwide [25,26]. Recently, enzootic withinfarm persistence of IAV-S has been described as consecutive waves of diverse intensity in some Spanish farrow-to-finish operations [27]. 
Moreover, pigs with passive immunity to IAV-S have been identified as potential disseminators of IAV-S, despite a potential reduction in clinical disease implied by this immunity [28]. Porcine circovirus type 2 is also responsible for considerable economic losses in the swine industry worldwide [29]. PCV-associated disease (PCVAD) can manifest as enteric, respiratory, reproductive, and systemic disease [30]. PCVAD is characterized by lymphoid depletion, which is considered the hallmark lesion [31]. This is thought to induce immunosuppression or immunomodulation in the host [32], leading to secondary infections with other viral or bacterial pathogens [3335]. A field study in Spain confirmed detection of PCV-2 in several types of respiratory samples [36].

A validated tracheobronchial sampling technique [37-40] applied for early detection of M. hyopneumoniae in pigs [41] has recently been used in combination with multiplex PCR for detection of several PRDC pathogens, such as PRRSV, IAV-S, PCV-2, PRCV, PCMV and A. pleuropneumoniae to collect samples in pigs of different age categories with clinical signs of respiratory disease [42]. Significant differences in PRDC pathogens prevalence among age categories and seasons were demonstrated using this TBS technique [42].

The aim of the present study was to apply the TBS technique in clinical diagnostic sampling on-farm in post-weaned pigs from 3-12 weeks of age with clinical signs of respiratory disease to determine farm level prevalence of major respiratory pathogens such as $M$. hyopneumoniae, PRRSV, IAV-S and PCV-2 in Belgium and the Netherlands during different seasons.

\section{Materials and Methods}

\section{Selection of study herds}

The diagnostic samples were collected from January 2018 to June 2021 in Belgium and the Netherlands. Sow herds were sampled by trained swine veterinarians from different local veterinary practices in both countries. Inclusion criteria were as following: presence of clinical signs of respiratory disease (coughing), at least 15 samples in post-weaned pigs from 3-12 weeks of age, and no use of antimicrobials active against $M$. hyopneumoniae in pigs less than 3 weeks of age and during the last 2 weeks prior to sampling. Prior to sampling, eligible post-weaned pigs were marked up by the swine farmer or herd veterinarian. In total, 600 sow herds were included in the study, distributed over different seasons and a 4-year sampling period (Table 1). In total, 9,000 post-weaned pigs with clinical signs of respiratory disease were sampled. Within each herds, post-weaned pigs were sampled in as many compartments and pens as possible.
Sampling was always performed by a swine veterinarian specifically trained on TBS sampling.

\section{Tracheobronchial swab (TBS) sampling procedure}

TBS sampling was performed as previously described $[38,39]$. Briefly, TBS were obtained through thorough fixation of the piglets with a nose snare, followed by use of a mouth opener. The TBS (aspiration tube, $50 \mathrm{~cm}, 12 \mathrm{CH}$; Medinorm GmbH, SpiesenElversberg, Germany) was subsequently inserted through the mouth, through the glottis down to the tracheobronchial split. Mucus was collected through gentle movement of the swab at the level of the tracheobronchial split and the swab was subsequently retrieved. The tip of the swab was collected in a sterile tube (MLS, Menen, Belgium) with $1 \mathrm{~mL}$ of sterile saline solution (Saline Solution 0.9\%; Eurovet, Heusden-Zolder, Belgium) and kept cool at $3^{\circ} \mathrm{C}$ until analysis within $48 \mathrm{~h}$ after sampling. Piglet samples were pooled per 3 for PCR analysis.

\section{Analysis of TBS swabs}

The material collected by the TBS was processed according to Strait et al. (2008). A multiplex PCR (mPCR) analysis was performed according to the standard operating procedure of the laboratory (IVD GmbH, Hannover, Germany). The mPCR included analysis of M. hyopneumoniae, PRRSV, IAV-S, and PCV-2. PCR results were reported as negative or positive for the presence of the different PRDC pathogens. A farm was categorized as pathogen-positive when at least 1 piglet pool was detected positive for that specific pathogen.

\section{Data categorization for seasonality}

In order to assess the variations among season, and infection dynamics of PRDC pathogens sampled, herds were categorized for seasonality based on date of sampling. Seasonality was implemented as the following: S1: Winter (21/12-20/03; $\mathrm{n}=239$ herds), S2: Spring (21/03-20/06; $\mathrm{n}=157$ herds), S3: Summer (21/06-20/09; $\mathrm{n}=87$ herds), and S4: Autumn (21/09-20/12; $\mathrm{n}=117$ herds) (Table 1).

\section{Results}

\section{Prevalence of PRDC pathogens in Belgium and the Netherlands}

The prevalence data of all detected PRDC pathogens in both countries are given in Figure 1. In Belgium, PRRSV had the highest prevalence in post-weaned piglets with $53.8 \%$ of the sampled farms detected PRRSV-positive, followed by M. hyopneumoniae (48.8\%) and IAV-S (40.3\%). Only $20.6 \%$ of the sampled farms with clinical signs of respiratory disease were detected PCV-2-positive during the post-weaning period. In the Netherlands, farms were similarly

Table 1: Number of swine farms in Belgium and the Netherlands sampled per year and per season during the entire study period from S1 2018 until S2 2021 , including total number of sampled farms per year and per season.

\begin{tabular}{|c|c|c|c|c|c|c|c|c|c|c|c|}
\hline \multirow[b]{3}{*}{ Season } & \multicolumn{5}{|c|}{ Belgium } & \multicolumn{5}{|c|}{ Netherlands } & \multirow{3}{*}{ Total/season } \\
\hline & \multicolumn{4}{|c|}{ Year } & \multirow{2}{*}{ Total/season } & \multicolumn{4}{|c|}{ Year } & \multirow{2}{*}{ Total/season } & \\
\hline & 2018 & 2019 & 2020 & 2021 & & 2018 & 2019 & 2020 & 2021 & & \\
\hline S1 & 10 & 33 & 18 & 24 & 85 & 49 & 75 & 24 & 5 & 154 & 239 \\
\hline S2 & 17 & 21 & 15 & 16 & 69 & 40 & 34 & 10 & 5 & 88 & 157 \\
\hline S3 & 13 & 13 & 9 & & 35 & 25 & 23 & 4 & & 52 & 87 \\
\hline S4 & 21 & 19 & 19 & & 59 & 30 & 24 & 4 & & 58 & 117 \\
\hline Total/year & 61 & 86 & 61 & 40 & 248 & 144 & 156 & 42 & 10 & 352 & 600 \\
\hline
\end{tabular}

S1: Winter; S2: Spring; S3: Summer, and S4: Autumn. 


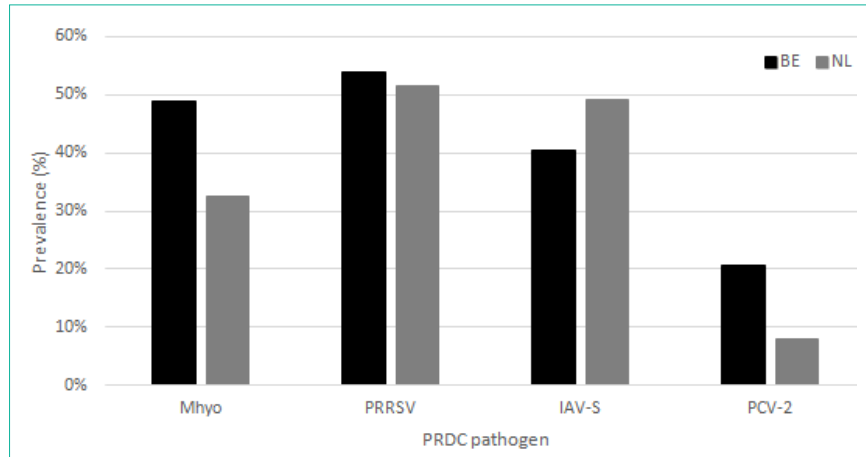

Figure 1: Prevalence (expressed as \% positive farms) of different single PRDC pathogens in post-weaned pigs (3-12 weeks of age) at farm level. In total, 9,000 pigs were sampled in 600 different farms distributed throughout Belgium $(n=248)$ and the Netherlands $(n=352)$ for diagnostic purposes of clinical respiratory disease.

PRRSV: Porcine Reproductive and Respiratory Syndrome Virus; M. hyo: Mycoplasma Hyopneumoniae; IAV-S: Influenza A Virus in Swine; PCV2: Porcine Circovirus Type 2.

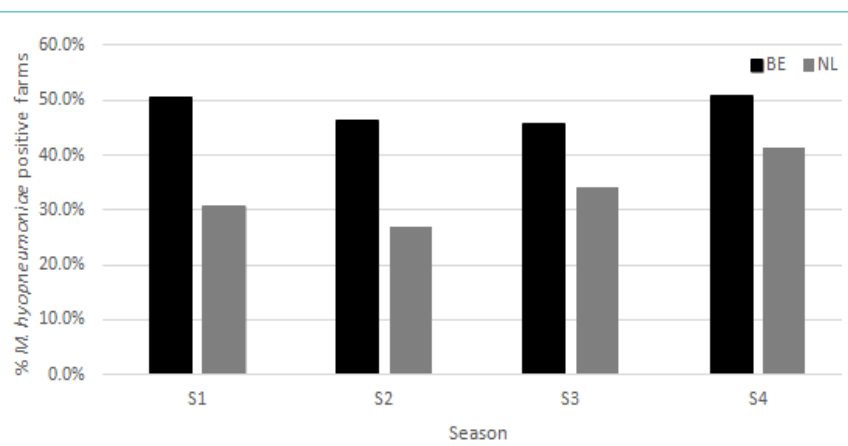

Figure 2: Prevalence (expressed as \% positive farms) of $M$. hyopneumoniae in post-weaned pigs (3-12 weeks of age) at farm level. In total, 9,000 pigs were sampled in 600 different farms distributed throughout Belgium $(n=248)$ and the Netherlands $(n=352)$ for diagnostic purposes of clinical respiratory disease.

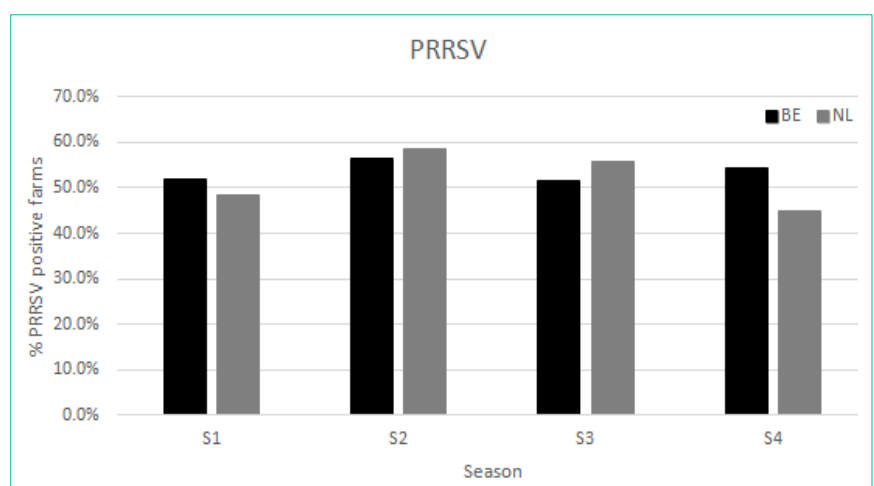

Figure 3: Prevalence (expressed as \% positive farms) of PRRSV in postweaned pigs (3-12 weeks of age) at farm level. In total, 9,000 pigs were sampled in 600 different farms distributed throughout Belgium $(n=248)$ and the Netherlands $(n=352)$ for diagnostic purposes of clinical respiratory disease.

positive for both PRRSV (51.4\%) and IAV-S (49.1\%) followed by $M$. hyopneumoniae (32.4\%). Again, a much lower percentage of farms were detected PCV-2 positive (8.0\%) during the post-weaning period.

Prevalence of double and triple PRDC major pathogen interactions
Table 2: Prevalence (expressed as \% positive farms) of different double, triple and multiple PRDC pathogen interactions in post-weaned pigs (3-12 weeks of age) at farm level. In total, 9,000 pigs were sampled in 600 different farms distributed throughout Belgium $(n=248)$ and the Netherlands $(n=352)$ for diagnostic purposes of clinical respiratory disease.

\begin{tabular}{|c|c|c|}
\hline & Belgium & Netherlands \\
\hline Double infections & & \\
\hline M. hyo - PRRSV & $10.90 \%$ & $11.10 \%$ \\
\hline$M$. hyo - IAV-S & $4.00 \%$ & $5.10 \%$ \\
\hline M. hyo - PCV-2 & $3.60 \%$ & $0.00 \%$ \\
\hline PRRSV - IAV-S & $11.30 \%$ & $18.20 \%$ \\
\hline PRRSV - PCV-2 & $1.20 \%$ & $3.10 \%$ \\
\hline IAV-S - PCV-2 & $0.40 \%$ & $1.10 \%$ \\
\hline Triple infections & & \\
\hline M. hyo - PRRSV - IAV-S & $6.90 \%$ & $6.30 \%$ \\
\hline M. hyo - PRRSV - PCV-2 & $7.30 \%$ & $0.60 \%$ \\
\hline PRRSV - IAV-S - PCV-2 & $1.20 \%$ & $2.30 \%$ \\
\hline Multiple infections & & \\
\hline M. hyo - PRRSV - IAV-S - PCV-2 & $4.00 \%$ & $0.60 \%$ \\
\hline
\end{tabular}

PRRSV: Porcine Reproductive and Respiratory Syndrome Virus; M. hyo: Mycoplasma Hyopneumoniae; IAV-S: Influenza A Virus in Swine; PCV2: Porcine Circovirus Type 2.

are given in Table 2. Most prevalent pathogen combinations during the post-weaning phase were M. hyopneumoniae - PRRSV (10.9 and $11.1 \%$ in Belgium and the Netherlands, respectively), PRRSV - IAV-S (11.3 and 18.2\% in Belgium and the Netherlands, respectively), and $M$. hyopneumoniae - IAV-S (4.0 and 5.1 in Belgium and the Netherlands, respectively) within the double infections and $M$. hyopneumoniae - PRRSV - IAV-S (6.9 and 6.3\% in Belgium and the Netherlands, respectively), and PRRSV - IAV-S - PCV-2 (1.2 and 2.3\% in Belgium and the Netherlands, respectively). The triple combination of $M$. hyopneumoniae - PRRSV - PCV-2 holds a particular position, since it was highly prevalent in Belgium (7.3\%) and only marginally detectable in the Netherlands (0.6\%). Multiple infections including all four analyzed pathogens were only present in $4.0 \%$ of the farms in Belgium and $0.6 \%$ in the Netherlands.

\section{Seasonal variation in prevalence of PRDC pathogens at piglet level}

Effect of season on farm prevalence of different PRDC pathogens is given in Figure 2-5. In Belgium, on average $48.8 \%$ of the farms was M. hyopneumoniae-positive. During both S4 (autumn) and S1 (winter), percentage of M. hyopneumoniae-positive farms was above $50 \%$, whereas in both other seasons, the percentage decreased to about $45-46 \%$ positivity. In the Netherlands, the overall percentage of M. hyopneumoniae-positive farms was much lower (32.4\%) with the highest percentages during S3 (summer; 34.0\%) and S4 (autumn; 41.4\%), followed by S1 (winter; 30.7\%). During spring (S2), only $27.0 \%$ of the sampled farms tested positive for M. hyopneumoniae (Figure 2).

For PRRSV, no relevant country differences could be observed in the overall percentage of PRRSV-positive farms (53.6 and 51.4\% in Belgium and the Netherlands, respectively). Highest percentages of PRRSV-positivity were observed during S2 (spring; 56.5 and $58.4 \%$ in Belgium and the Netherlands, respectively). The other seasons were 


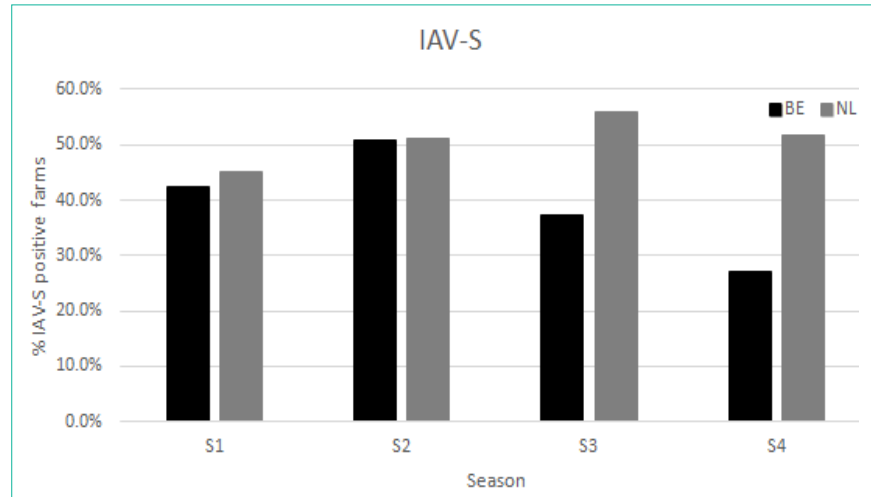

Figure 4: Prevalence (expressed as $\%$ positive farms) of AIV-S in postweaned pigs (3-12 weeks of age) at farm level. In total, 9,000 pigs were sampled in 600 different farms distributed throughout Belgium $(n=248)$ and the Netherlands $(n=352)$ for diagnostic purposes of clinical respiratory disease.

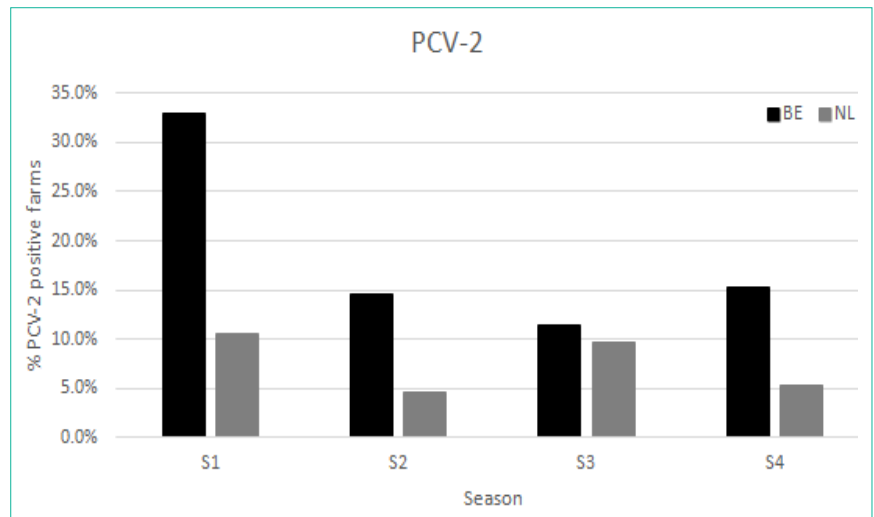

Figure 5: Prevalence (expressed as \% positive farms) of PCV-2 in postweaned pigs (3-12 weeks of age) at farm level. In total, 9,000 pigs were sampled in 600 different farms distributed throughout Belgium $(n=248)$ and the Netherlands $(n=352)$ for diagnostic purposes of clinical respiratory disease.

slightly lower in their percentage of PRRSV-positive farms and varied a little between Belgium and the Netherlands ranging from 44.8 to $54.2 \%$ as most extreme values (Figure 3 ).

The overall percentage of IAV-S-positive farms was higher in the Netherlands (49.1\%) as compared to Belgium (40.3\%), which was mostly explainable by the much higher percentages of IAV-Spositive farms observed during S3 (summer; 55.8\%) and S4 (autumn; $51.7 \%$ ) in the Netherlands as compared to Belgium (S3, 37.1\% and S4, 27.1\%,). During S1 (winter) and S2 (spring), the percentage of IAV-S-positive farms were quite similar in both countries (Figure 4).

Finally, we observed remarkable differences in the percentage of PCV-2-positive farms between Belgium and the Netherlands, both overall (20.6 and 8.0\% in Belgium and the Netherlands, respectively) and among the different seasons. In Belgium, the highest percentage of PCV-2-positive farms was observed in S1 (winter; 32.9\%), followed by S4 (autumn; 15.3\%) and S2 (14.5\%). During S3 (summer), only $11.3 \%$ of the farms were PCV-2-positive. In the Netherlands, the highest percentage was again observed during S1 (winter; 10.5\%) and S3 (summer; 9.6\%), whereas during S2 (spring; 4.5\%) and S4 (autumn; 5.3\%) the percentages were much lower (Figure 5).

\section{Discussion}

Porcine respiratory disease complex remains one of the most important health concerns with a high economic impact for pig producers worldwide. The disease involves multiple viral and bacterial pathogens together with several non-infectious factors, such as ventilation, housing conditions, and management, leading to respiratory distress in pigs during different stages of production, including the post-weaning period. Interaction between both infectious (viral and bacterial agents) and non-infectious factors may all contribute to the development and severity of the respiratory disease [24]. The most commonly identified pathogens are PRRSV, IAV-S, PCV-2, and M. hyopneumoniae, besides other pathogens associated with PRDC, such as $S$. suis, A. pleuropneumoniae, $P$. multocida, DNT-positive P. multocida, G. parasuis, M. hyorhinis, M. hyosynoviae, PRCV, and PCMV [3,23-28,42]. Detection of the etiologic agents of PRDC has long been difficult, especially due to the wide variety of diagnostic approaches applied in practice. Diagnosis of M. hyopneumoniae could be performed using clinical signs, slaughterhouse checks of affected lungs $[43,44]$, serological examination of relevant age groups [43,44], direct pathogen identification through bacteriological culture [37] or PCR techniques $[45,46]$. As for other respiratory pathogens involved in PRDC, more or less the same diagnostic approach has been applied, mainly due to lack of diagnostic tests able to simultaneously detect multiple respiratory pathogens in a single-reaction method [6]. Although these single pathogen detection techniques may be reliable and sensitive, they remain time-consuming, labor-intensive, and therefore, quite expensive. Moreover, for bacterial pathogens, detection typically depends on culture-based methods that can take up to several days to obtain the final results.

Polymerase chain reactions and real-time PCR tests have been developed for several pathogens involved in PRDC and are characterized by their high sensitivity and ease of use. In combination with a reliable sampling technique, such as TBS, these detection methods based on PCR have been able to detect M. hyopneumoniae at an early age $[38,39]$ and in an early stage of infection $[40,41]$.

The results from the current study in 600 pig farms clearly demonstrate that post-weaned piglets can be infected at an early stage with M. hyopneumoniae, which is in accordance with previous reports applying the same sampling technique [39]. However, besides M. hyopneumoniae, other major pathogens related to PRDC may be involved in the clinical picture of coughing post-weaned piglets (3-12 weeks of age), such as IAV-S, PRRSV, and to a lesser extent PCV-2. In contrast to a previous study [43], we analyzed the results at farm level, designating a farm as positive to a specific pathogen when at least one of the pools of sampled post-weaned piglets was detected positive for that specified pathogen. Therefore, we can not entirely compare the farm prevalence levels observed in the present study with the piglet prevalence levels from the previous study.

In contrast to previous studies [38-41], where sampling was focused on M. hyopneumoniae detection and prevalence only, the current study clearly demonstrates that $M$. hyopneumoniae is in many cases combined with other pathogens related to PRDC. The demonstrated presence of $M$. hyopneumoniae during the postweaning period might significantly impact the clinical course of other 
PRDC pathogens such as PRRSV [9,10], IAV-S $[2,11,12]$, or PCV-2 $[14,15]$.

There were clear differences in the prevalence of pathogen-positive farms between Belgium and the Netherlands for M. hyopneumoniae, IAV-S and PCV-2, whereas for PRRSV the results tended to be similar. For both M. hyopneumoniae and PCV-2, differences in piglet vaccination level can not entirely explain the difference in percentage of positive farms between both countries. Since the vaccination level for M. hyopneumoniae in Belgium is higher than in the Netherlands, we would expect the level of $M$. hyopneumoniae-positive farms to be lower in Belgium. However, in the current study, we classified a farm as positive when at least one piglet pool tested positive for the pathogen, and therefore, the in-farm prevalence was not really taken into account. Indeed, previous studies under both experimental [47] and field [48] conditions have shown that piglets vaccinated for $M$. hyopneumoniae during the suckling period and subsequently infected with $M$. hyopneumoniae during the post-weaning period excrete lower amounts of M. hyopneumoniae and therefore have a reduced $\mathrm{R} 0$ for M. hyopneumoniae. This observation was confirmed during an experimental vaccination-infection trial enrolling piglets from birth till slaugher age. Piglets vaccinated for M. hyopneumoniae at early age excrete $2 \log 10$ less M. hyopneumoniae as compared to unvaccinated control pigs [13]. The same study also demonstrated a significant reduction of about $4 \log 10$ in the level of PCV-2 in vaccinated piglets as compared to unvaccinated controls [13].

For IAV-S, the difference between Belgium and the Netherlands might be explained by the size of sow herds. Since IAV-S can endemically circulate in sow herds, larger herds tend to more prone to continuous circulation during the post-weaning phase. This is mainly due to the fact that larger herds wean piglets that might become susceptible to IAV-S post-weaning, on a weekly basis. In contrast, smaller herds rather operate according to batch-management systems with intervals between consecutive batches of 2, 3, 4 or 5 weeks, creating a gap that might potentially reduce circulation of infection. For PRRSV, we previously demonstrated that changes in farm management system without clear adaptations in internal biosecurity did not have an impact on the kinetics of PRRSV at farm level.

Seasonal variations could be observed for all PRDC pathogens analyzed in the current study. For M. hyopneumoniae, the seasonal variation in percentage of farms positive for the pathogen are less pronounced as compared to the variations that could be observed on a piglet level in our previous study, although the same trend could be observed. The level of M. hyopneumoniae-positivity was highest during autumn and winter, and lower during spring and summer, when weather conditions in our region are less favorable for M. hyopneumoniae transmission between animals and farms [49]. For PRRSV, the seasonal variations were very discrete as the seasonal percentage varied between 51.4 and $56.5 \%$ in Belgium and 44.8 and $58.4 \%$ in the Netherlands. For IAV-S, seasonal variation is more pronounced under Belgium conditions, with lower levels in summer and autumn and increased levels during winter and spring, mainly due to the cold and humid conditions favorable for virus transmission [49]. The seasonal variations observed for PCV-2 were less prominent due to the lower percentage of PCV-2-positive farms in both countries. The lower level of PCV-2 during the post-weaning period is in accordance with a previous study [50] on serological and viral dynamics of PCV-2 carried out in PCV-2 infected pig herds in Taiwan, where prevalence was around $11.2 \%$ in growing pigs $[51,52]$.

The present study clearly shows that several viral and bacterial pathogens responsible for PRDC may be present during the postweaning period. Following analysis of seasonal variation, it can be concluded most pathogens show a seasonal pattern with a higher percentage of farms positive during autumn and winter, which has more favorable conditions for longer survival and better transmission of pathogens between animals and farms in our region.

\section{Conclusion}

In conclusion, the present study showed that many respiratory pathogens are present during the post-weaning period, which may complicate the clinical picture of respiratory disease.

\section{References}

1. Maes D, Deluyker H, Verdonck M, Castryck F, Miry C, Vrijens B, et al. Herd factors associated with the seroprevalences of four major respiratory pathogens in slaughter pigs from farrow-to-finish pig herds. Vet. Res. 2000 31: 313-327.

2. Thacker EL. Immunology of the porcine respiratory disease complex. Vet. Clin. N. Am. Food Anim. Pract. 2001 17: 551-565.

3. Hansen MS, Pors SE, Jensen HE, Bille-Hansen V, Bisgaard M, Flachs EM, et al. An investigation of the pathology and pathogens associated with porcine respiratory disease complex in Denmark. J. Comp. Pathol. 2010 143: 120131.

4. Hernandez-Garcia J, Robben N, Magnée D, Eley T, Dennis I, Kayes SM et al. The use of oral fluids to monitor key pathogens in porcine respiratory disease complex. Porc. Health Manag. 2017; 3: 7-12.

5. Fablet C, Marois-Créhan C, Simon G, Grasland B, Jestin A, Kobisch M, et al. Infectious agents associated with respiratory diseases in 125 farrow-to-finish pig herds: A cross-sectional study. Vet. Microbiol. 2012; 157: 152-163.

6. Sunaga F, Tsuchiaka S, Kishimoto M, Aoki H, Kakinoki M, Kure K, et al. Development of a one-run real-time PCR detection system for pathogens associated with porcine respiratory diseases. J. Vet. Med. Sci. 2020; 82: 217223.

7. Sibila M, Pieters M, Molitor T, Maes D, Haesebrouck F, Segalés J. Current perspectives on the diagnosis and epidemiology of Mycoplasma hyopneumoniae infection. Vet. J. 2009; 181: 221-231.

8. Maes D, Sibila M, Kuhnert P, Segalés J, Haesebrouck F, Pieters M. Update on Mycoplasma hyopneumoniae infections in pigs: Knowledge gaps for improved disease control. Transbound. Emerg. Dis. 2017; 62: 1-15.

9. Fano E, Pijoan C, Dee S. Infection dynamics of porcine reproductive and respiratory syndrome virus in a continuous-flow population of pigs also infected with Mycoplasma hyopneumoniae. Vet. Rec. 2007; 161: 515-520.

10. Park S-J, Seo HW, Park C, Chae C. Interaction between single-dose Mycoplasma hyopneumoniae and porcine reproductive and respiratory syndrome virus vaccines on dually infected pigs. Res. Vet. Sci. 2014; 96: 516-522.

11. Deblanc C, Gorin S, Quéguiner S, Gautier-Bouchardon AV, Ferré S, Amenna $\mathrm{N}$, et al. Pre-infection of pigs with Mycoplasma hyopneumoniae modifies outcomes of infection with European swine influenza virus of $\mathrm{H} 1 \mathrm{~N} 1$, but not H1N2 subtype. Vet. Microbiol. 2012; 157: 96-105.

12. Deblanc C, Robert F, Pinard T, Gorin S, Quéguiner S, Gautier-Bouchardon AV, et al. Pre-infection of pigs with Mycoplasma hyopneumoniae induces oxidative stress that influences outcomes of a subsequent infection with a swine influenza virus of H1N1 subtype. Vet. Microbiol. 2013; 162: 643-651.

13. Kim D, Kim CH, Han K, Seo HW, Oh Y, Park C, et al. Comparative efficacy of commercial Mycoplasma hyopneumoniae and porcine circovirus 2 (PCV2) vaccines in pigs experimentally infected with M. hyopneumoniae and PCV2. Vaccine. 2011; 29: 3206-3212. 
14. Opriessnig T, Thacker EL, Yu S, Fenaux M, Meng X-J, Halbur PG. Experimental reproduction of postweaning multisystemic wasting syndrome in pigs by dual infection with Mycoplasma hyopneumoniae and porcine circovirus type 2. Vet. Pathol. 2004; 41: 624-640.

15. Rossow KD. Porcine reproductive and respiratory syndrome. Vet. Pathol. 1998; 35: 1-20.

16. Thacker EL, Halbur PG, Ross RF, Thanawongnuwech R, Thacker BJ. Mycoplasma hyopneumoniae potentiation of porcine reproductive and respiratory syndrome virus-induced pneumonia. J. Clin. Microbiol. 1999; 37 620-627.

17. Brockmeier SL, Palmer MV, Bolin SR. Effects of intranasal inoculation of porcine reproductive and respiratory syndrome virus, Bordetella bronchiseptica, or a combination of both organisms in pigs. Am. J. Vet. Res. 2000; 61: 892-899.

18. Drew TW. A review of evidence for immunosuppression due to porcine reproductive and respiratory syndrome virus. Vet. Res. 2000; 31: 27-39.

19. Halbur PG, Thanawongnuwech R, Brown G, Kinyon J, Roth J, Thacker E, et al. Efficacy of antimicrobial treatments and vaccination regimens for control of porcine reproductive and respiratory syndrome virus and Streptococcus suis coinfection of nursery pigs. J. Clin. Microbiol. 2000; 38: 1156-1160.

20. Labarque G, Van Reeth K, Van Gucht S, Nauwynck H, Pensaert M Porcine reproductive-respiratory syndrome virus infection predisposes pigs for respiratory signs upon exposure to bacterial lipopolysaccharide. Vet. Microbiol. 2002; 88: 1-12

21. Renukaradhya GJ, Alekseev K, Jung K, Fang Y, Saif LJ. Porcine reproductive and respiratory syndrome virus-induced immunosuppression exacerbates the inflammatory response to porcine respiratory coronavirus in pigs. Viral Immunol. 2010; 23: 457-466.

22. Segalés J, Calsamiglia M, Rosell C, Soler M, Maldonado J, Martin M, et al. Porcine reproductive and respiratory syndrome virus (PRRSV) infection status in pigs naturally infected with post-weaning multisystemic wasting syndrome (PMWS) in Spain. Vet. Microbiol. 2002; 85: 23-30.

23. Rovira A, Balasch M, Segalés J, Garcia L, Plana-Duran J, Rosell C, et al. Experimental inoculation of conventional pigs with porcine reproductive and respiratory syndrome virus and porcine circovirus 2. J. Virol. 2002; 76: 3232 3239.

24. Opriessnig T, Giménez-Lirola LG, Halbur PG. Polymicrobial respiratory disease in pigs. Anim. Health Res. Rev. 2011; 12: 133-148.

25. Olsen CW, Brown IH, Easterday BC, Van Reeth K. Swine Influenza. In Diseases of Swine, $9^{\text {th }}$ ed. Straw B, Zimmerman W, D'Allaire S, Taylor D, Eds. Iowa State University Press: Ames, IA, USA. 2006: 469-482.

26. Kuntz-Simon G, Madec F. Genetic and antigenic evolution of swine influenza viruses in Europe and evaluation of their zoonotic potential. Zoonoses Public Health. 2009; 56: 310-325.

27. Simon-Grife M, Martin-Valls GE, Vilar MJ, Busquets N, Mora-Salvatierra M, Besteboer TM, et al. Swine influenza virus infection dynamics in two pigs farms: Results of a longitudinal assessment. Vet. Res. 2012; 43: 24

28. Allerson M, Deen J, Detmer SE, Gramer MR, Joo HS, Romagosa A, et al The impact of maternally derived immunity on influenza A virus transmission in neonatal pig populations. Vaccine. 2013; 31: 500-505.

29. Segalès J, Allan GM, Domingo M. Porcine circovirus diseases. Anim. Health Res. Rev. 2005a; 6: 119-142.

30. Opriessnig T, Meng XJ, Halbur PG. Porcine circovirus type 2 associated disease: Update on current terminology, clinical manifestations, pathogenesis diagnosis, and intervention strategies. J. Vet. Diagn. Invest. 2007; 19: 591 615

31. Segalés J, Rosell C, Domingo M. Pathological findings associated with naturally acquired porcine circovirus type 2 associated disease. Vet. Microbiol. 2004; 98: 137-149.

32. Darwich L, Pie S, Rovira A, Segalés J, Domingo M, Oswald IP, et al. Cytokine mRNA expression profiles in lymphoid tissues of pigs naturally affected by postweaning multisystemic wasting syndrome. J. Gen. Virol. 2003; 84: 2117 2125 .

33. Pallarés FJ, Halbur PG, Opriessnig T, Sorden SD, Villar D, Janke BH, et al. Porcine circovirus type 2 (PCV-2) coinfections in US field cases of postweaning multisystemic wasting syndrome (PMWS). J. Vet. Diagn. Investig. 2002; 14: 515-519

34. Kim J, Chung HK, Chae C. Associations of porcine circovirus 2 with porcine respiratory disease complex. Vet. J. 2003; 166: 251-256.

35. Dorr PM, Baker RB, Almond GW, Wayne SR, Gebreyes WA. Epidemiologic assessment of porcine circovirus type 2 coinfection with other pathogens in swine. J. Am. Vet. Med. Assoc. 2007; 230: 244-250.

36. Segalés J, Calsamiglia $M$, Olvera $A$, Sibila $M$, Badiella L, Domingo $M$. Quantification of porcine circovirus type 2 (PCV2) DNA in serum and tonsillar, nasal, trachea-bronchial, urinary and fecal swabs of pigs with and without postweaning multisystemic wasting syndrome (PMWS). Vet. Microbiol. 2005b; 111: 223-229.

37. Marois C, Le Carrou J, Kobisch M, Gautier-Bouchardon AV. Isolation of Mycoplasma hyopneumoniae from different sampling sites in experimentally infected and contact SPF pigs. Vet. Microbiol. 2007; 120: 96-104.

38. Vangroenweghe F, Karriker L, Main R, Christianson E, Marsteller T, Hammen $\mathrm{K}$, et al. Assessment of litter prevalence of Mycoplasma hyopneumoniae in preweaned piglets utilizing an antemorten tracheobronchial mucus collection technique and real-time polymerase chain reaction assay. J. Vet. Diagn. Investig. 2015; 27: 606-610.

39. Vangroenweghe FACJ, Labarque GL, Piepers S, Strutzberg-Minder K, Maes D. Mycoplasma hyopneumoniae infections in peri-weaned and post-weaned pigs in Belgium and The Netherlands: Prevalence and associations with climatic conditions. Vet. J. 2015; 205: 93-97.

40. Vangroenweghe F. Early Detection of Mycoplasma hyopneumoniae under Field Conditions. Ph.D. Thesis, Applied Biological Sciences, Ghent University, Ghent, Belgium. 2018: 1-205.

41. Vangroenweghe F, Willems E, Malásek J, Thas O, Maes D. Use of tracheabronchial swab qPCR testing to confirm Mycoplasma hyopneumoniae seropositivity in an SPF breeding herd. Porc. Health Manag. 2018; 4: 12-17.

42. Vangroenweghe F, Willems E, Thas O, Maes D. Short communication: Confirmation of Mycoplasma hyopneumoniae in a breeding herd through tracheo-bronchial swab sampling and PCR. Vet. Rec. 2018; 183: 325.

43. Fraile L, Alegre A, López-Jiménez R, Nofrarías M, Segalés J. Risk factors associated with pleuritic and cranio-ventral pulmonary consolidation in slaughter-age pigs. Vet. J. 2010; 184: 326-333.

44. Meyns T, Van Steelant J, Rolly E, Dewulf J, Haesebrouck F, Maes D. A crosssectional study of risk factors associated with pulmonary lesions in pigs at slaughter. Vet. J. 2011; 187: 388-392.

45. Calsamiglia M, Pijoan C, Trigo A. Application of a nested polymerase chain reaction assay to detect Mycoplasma hyopneumoniae from nasal swabs. J. Vet. Diagn. Investig. 1999; 11: 246-251.

46. Marois C, Dory D, Fablet C, Madec F, Kobish M. Development of a quantitative Real-Time TaqMan PCR assay for determination of the minimal dose of Mycoplasma hyopneumoniae strain 116 required to induce pneumonia in SPF pigs. J. Appl. Microbiol. 2010; 108: 1523-1533.

47. Meyns T, Dewulf J, de Kruif A, Calus D, Haesebrouck F, Maes D. Comparison of transmission of Mycoplasma hyopneumoniae in vaccinated and nonvaccinated populations. Vaccine. 2006; 24: 7081-7086.

48. Villarreal I, Meyns T, Dewulf J, Vranckx K, Calus D, Pasmans F, et al. The effect of vaccination on the transmission of Mycoplasma hyopneumoniae in pigs under field conditions. Vet. J. 2010; 188: 48-52.

49. Dee S, Otake S, Deen J. Use of a production region model to assess the efficacy of various air filtration systems for preventing airborne transmission of porcine reproductive and respiratory syndrome virus and Mycoplasma hyopneumoniae: Results from a 2-year study. Virus Res. 2010; 154: 177-184.

50. Lin C-N, Ke N-J, Chiou M-T. Cross-sectional study on the sero- and viral 
dynamics of porcine circovirus type 2 in the field. Vaccines. 2020; 8: 339-351.

51. Calsamiglia M, Pijoan C. Colonisation state and colostral immunity to Mycoplasma hyopneumoniae of different parity sows. Vet. Rec. 2000; 146: $530-532$
52. Fablet C, Marois C, Kobisch M, Madec F, Rose N. Estimation of the sensitivity of four sampling methods for Mycoplasma hyopneumoniae detection in live pigs using a Bayesian approach. Vet. Microbiol. 2010; 143: 238-245. 